\title{
LOS ARZOBISPOS DE LA \\ Arquidiócesis de Bogotá \\ Y LOS JESUITAS EN EL SIGLO XIX
}

Jorge Enrique Salcedo Martínez, S. J.

\section{INTRODUCCIÓN}

En el siglo XIX cinco arzobispos de la Arquidiócesis de Bogotá brindaron las condiciones de posibilidad para que la Compañía de Jesús retornara y posteriormente se estableciera definitivamente en la nueva República. Los jesuitas habían sido expulsados del Nuevo Reino de Granada por decreto real en 1767 y luego por la presión de las monarquías borbónicas fueron suprimidos de la Iglesia Universal por el papa Clemente XIV en 1773. El 7 de agosto de 1814 el papa Pío VII los volvió a restaurar. En España los jesuitas fueron restaurados por el rey Fernando VII mediante los decretos de 29 de mayo de 1815 y de 3 de mayo de 1816 y más adelante, en los dominios españoles de Ultramar con el decreto de 19 de septiembre de 1815. Con este hecho los jesuitas retornaron a aquellos lugares donde habían hecho presencia durante el periodo hispánico. Tal es el caso de la joven república de la
Nueva Granada (Revuelta, 2006, pp. 209-258), adonde la Compañía de Jesús retornó gracias a las gestiones del arzobispo Manuel José Mosquera y de su hermano Manuel María (que en un primer momento ayudó en el proceso), así como del presidente Pedro Alcántara Herrán y su ministro del interior Mariano Ospina Rodríguez. Gracias a la ayuda del prelado Mosquera, los jesuitas estuvieron presentes en la Nueva Granada entre 1844 y 1850 . En este año como una de las medidas intervencionistas contra la Iglesia católica, el gobierno de José Hilario López expulsó a los religiosos argumentando que la pragmática de Carlos III estaba vigente en la República (López, 1850).

Durante el tiempo de la Confederación Granadina, el arzobispo Antonio Herrán y Zaldúa hizo las gestiones ante el superior general de los jesuitas Pedro Beckx para que estos regresaran de nuevo al país en 
1858. En esta ocasión los jesuitas se establecieron únicamente en la ciudad de Bogotá y allí estuvieron hasta una tercera expulsión promovida en este caso por el general Tomás Cipriano de Mosquera en 1861.

El siguiente arzobispo, Vicente Arbeláez, apoyó a un grupo de jesuitas que hacían presencia en la ciudad de Bogotá en 1883. Después del deceso de Arbeláez su sucesor fue el obispo de Panamá, monseñor José Telésforo Paúl, jesuita que había sido nombrado en esa diócesis en 1876. Paúl como arzobispo de Bogotá ayudó a consolidar la presencia definitiva de los jesuitas en el país y jugó un papel muy importante en la Constitución de 1886 y en la elaboración del Concordato con la Santa Sede de 1887. El siguiente arzobispo, Ignacio León Velasco, también de la Compañía y que se había desempeñado como obispo de Pasto desde marzo de 1883, les devolvió a los jesuitas la iglesia de San Carlos, desde ese momento conocida como iglesia de San Ignacio.

Fue gracias a las gestiones de estos arzobispos que los jesuitas pudieron retornar y establecerse definitivamente en el país. Dadas estas características generales expondremos el apoyo que recibieron los jesuitas de estos arzobispos.

\section{Monseñor Manuel José Mosquera, arzobispo de Bogotá, 1835-1853}

A su arribo a la sede arquidiocesana de Bogotá en 1835, monseñor Manuel José Mosquera ${ }^{1}$ se encontró con dos realidades: por un lado, el abandono y la incuria en la que -a su juicio- vivían la gran mayoría de los fieles a causa de la falta de educación cristiana; y por el otro, la precaria situación del clero debido a la escasez de sacerdotes y a las dudosas condiciones en las que se daba su formación.

${ }^{1}$ Manuel José Mosquera nació en Popayán el 11 de abril de 1800 y murió en Marsella, Francia, el 10 de diciembre de 1853. Sus estudios los inició en Popayán pero debido a la inestabilidad política del sur de la actual Colombia, sus padres lo enviaron al seminario San Luis de Quito donde obtuvo los grados de bachiller en filosofía, licenciado y doctor. En 1823 regresó a su ciudad natal donde fue ordenado sacerdote (Dueńas, 2004, pp. 9-33). En su ciudad desempeñó cargos como vicerrector y rector de la Universidad del Cauca. En 1832, el papa Gregorio XVI lo nombró prelado doméstico asistente al solio pontificio. El 27 de abril de 1834 el Congreso de la República de la Nueva Granada en ejercicio de la ley de patronato dirigió a la Santa Sede una petición para que lo nombrara arzobispo. Fue consagrado obispo en Popayán en 1835 y luego fue arzobispo de la Arquidiócesis de Santafé de Bogotá entre 1835 y 1853 (Arboleda, 1956, pp. 17-45). Su elección como arzobispo fue vista por la prensa oposicionista y por José María Obando como una intervención de Tomás Cipriano de Mosquera en el gobierno, aprovechando su origen familiar aristocrático (continúa en la página 240). 
Figura 1. Vienot. (Siglo XX). Arzobispo Manuel José Mosquera. Bogotá: Archivo Capitular Catedral Primada de Colombia.

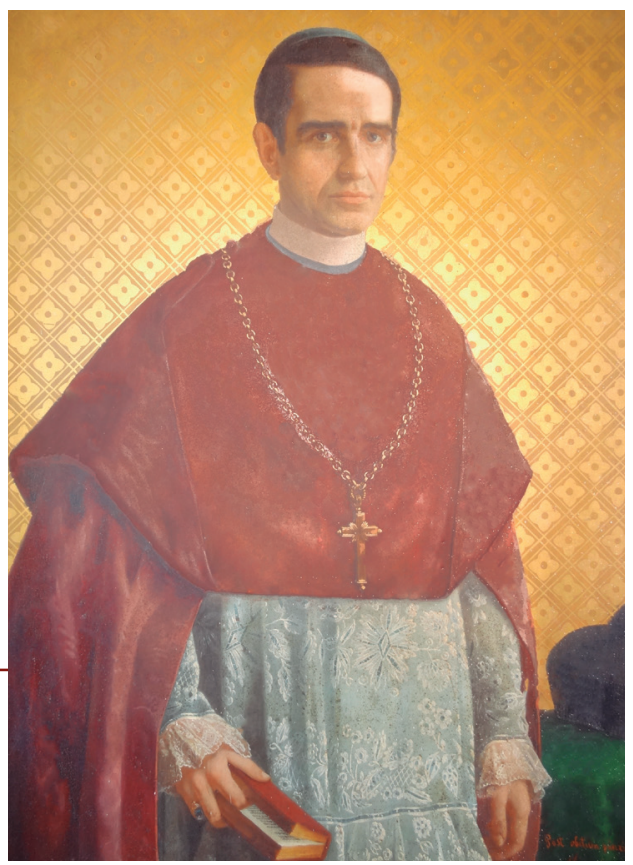

Sobre el deplorable estado de sus feligreses, el arzobispo Mosquera dejó consignada una visión por demás pesimista, tal como señaló en una carta dirigida a Rufino Cuervo: "Nuestra sociedad, digámoslo con franqueza, está enferma, y lo está precisamente por la mala educación, por la falta de educación cristiana, por las doctrinas subversivas que la ganan como la gangrena" (Cuervo, 1922, p. 96). El Arzobispo quizá tenía razón sobre esta percepción, pues llegaba a una arquidiócesis inmensa, cuyo territorio abarcaba las antiguas provincias de Bogotá, Tunja, Socorro, Pamplona, Mariquita y Neiva. Su población se calculaba aproximadamente en un millón de habitantes y sus feligreses habían recibido la última visita pastoral del arzobispo Baltasar Jaime Martínez de Compañón unos cuarenta años atrás (Arboleda, 1956, p. 56).

En cuanto a la educación del poco clero secular y regular existente en el país, es evidente en la correspondencia privada de monseñor Mosquera cierta desconfianza con la calidad de la formación intelectual, eclesiástica y moral recibida por el clero antes de 1835 (Mantilla, 2004, p. 216). Según reflexionaba el Arzobispo, los religiosos locales habían recibido una formación heterodoxa, en gran parte debido al decreto de Simón Bolívar del 5 de julio de 1820, el cual estipuló que el Gobierno, en uso de su derecho al Patronato, manejara directamente los colegios. La medida implicó que planteles hasta entonces 
regentados por miembros de la Iglesia y de las órdenes religiosas, pasaran a ser dirigidos por funcionarios civiles de los nuevos gobiernos republicanos. Así, desde el Rosario y San Bartolomé en Bogotá, hasta el colegio de Popayán y otros colegios provinciales, estas instituciones tuvieron que implementar las reformas del nuevo plan de estudios de Francisco de Paula Santander, el cual promovía la enseñanza -entre otros autores- de Jeremy Bentham.

Ante este panorama, dentro de los objetivos de gobierno presentados en su primera carta pastoral, el Arzobispo propuso no solo cultivar "la piedad, la ciencia y la virtud" del clero, sino educar cristianamente a los niños, "los predilectos de Jesucristo, de la Iglesia y de la República", de tal manera que se pudieran reparar todos aquellos "desastres y desgracias" vividos en el país (Mosquera, 1858, pp. 33-41). Para cumplir tales propósitos, Mosquera elaboró "un programa para la educación más sistemática, soluciones pacíficas para los problemas nacionales y para reforzar las relaciones armónicas entre el Estado y la Iglesia” (Horgan, 1977, p. 29). A pesar de ello, en sus escritos y correspondencia resalta una desalentadora percepción del estado de la Arquidiócesis. En cartas a su hermano Tomás Cipriano, se lamentaba por no tener influencia en la formación de los jóvenes seminaristas; además señalaba que la gran mayoría del clero no lo estimaba ni hacía caso a sus exhortaciones. Sobre la realidad vivida por los jóvenes aspirantes al sacerdocio en las escuelas de las universidades, en otra carta a su amigo Rufino Cuervo el prelado dijo:

En San Bartolomé, lejos de formarse clérigos se crían enemigos del clero, imbuidos en los principios de Bentham; y aunque ese colegio es seminario, el arzobispo no tiene influencia para nada; el menos se considera dependiente del gobierno, que es quien manda en jefe. ¿Qué podré yo hacer? Sufrir y esperar que Dios disponga otra cosa ${ }^{2}$.

Para muchos este nombramiento confirmaba la idea de que el prelado era un instrumento político del General. A este respecto, el clérigo de la catedral José Manuel Fernández Saavedra publicó un opúsculo en donde señalaba que el arzobispo había sido nombrado para ese cargo por "las intrigas de que se valió el señor Tomás C. Mosquera, que ocupaba el ańo de 34 un asiento en las Cámaras, para que no el benemérito seńor Estéves, Obispo de Santa Marta, sino su hermano Manuel José, fuese electo, son hoy ya bien sabidas; y que el mismo señor Mosquera contra la ley y la decencia votó por su hermano" (Cfr. Fernández, 1852, p. 5).

${ }^{2}$ Carta de Manuel José Mosquera a Rufino Cuervo. Marzo 13 de 1836 (Citado en Pacheco, 1946, p. 91). 
Para remediar esta situación Mosquera no vio más salida que formar a su clero en otro seminario, para lo cual dio vida el 4 de octubre de 1840, después de una solemne inauguración, al Seminario de San José. En este recinto se pretendía formar a las nuevas generaciones de clérigos conforme a las enseñanzas de la Iglesia y las directrices de Roma, para que estos fueran cultos, piadosos y entregados a la instrucción. El plan de estudios incluía clases de latín (lengua en la que se dictaban las clases de las facultades mayores), francés e inglés. La formación de los seminaristas quedó estructurada en tres años de filosofía con estudios auxiliares de matemáticas, física, nociones generales de agricultura, cosmografía y arquitectura. Para los estudios teológicos se adoptó la teología dogmática y moral, el derecho canónico, la sagrada escritura, la historia eclesiástica y la teología pastoral. El primer rector de este seminario fue el doctor Carlos Calvo (Cuervo, 1922, p. 94).

No obstante la creación de este nuevo seminario, la escasez de sacerdotes en la Nueva Granada se hizo aún más patente una vez finalizada la guerra de los Supremos (1839-1842). Por este y otros motivos el Arzobispo se convirtió en uno de los partidarios y entusiastas de la ley de creación de colegios de misiones y casas de escala, proyecto para el cual fueron finalmente escogidos los jesuitas. Si bien monseñor Mosquera no había estudiado en ninguna de las instituciones educativas de la Compañía, sí tenía conocimiento de la historia y de la literatura que había aparecido en Francia en defensa de esta orden, entre la cual se destacaba la famosa apología escrita por Gustave de Ravignan S. J. (1845). También fue determinante el importante papel desempeñado por los jesuitas en la labor misionera y en la educación de la juventud durante la época de la dominación española, tal como lo relevó el propio Arzobispo en un artículo publicado en el periódico El Día, en el cual mostraba el estado de decadencia de la misiones entre la población indígena una vez que estos religiosos las abandonaron, obedeciendo el decreto real que los expatrió del territorio neogranadino (El Día 1842).

Según uno de sus biógrafos, Mosquera mismo redactó el proyecto de ley que hizo posible el regreso de los religiosos al país (Arboleda, 1956, p. 178). El Arzobispo no estuvo solo en este propósito de restablecer una educación en el cristianismo y en la moral católica. Al lado de él se conformó un grupo de moderados católicos como Ignacio Gutiérrez Vergara, que en una carta dirigida a Cuervo dice, entre otros asuntos:

[...] y tengo la firme intención aunque pase por retrógrado y ultramontano de hacer cuanto pueda en el Congreso para volver a traer a la Nueva Granada los jesuitas misioneros. Si lo lograre, me 
parece que Pantaleón podrá vivir en una atmósfera menos contagiosa, aunque no ilustrada como la que respiramos. Yo estoy por lo real y positivo, y por esto entiendo la educación religiosa, única que puede hacer nuestra felicidad aquí, y más allá de aquí. Todo lo demás son dibujos y majaderías que no se echan a la olla. Creo que usted pensará lo mismo con respecto a sus hijos (Cuervo, 1922, pp. 227-228).

En otra carta que monseñor Mosquera le envía a Cuervo el 11 de mayo de 1842, le expresa su sentimiento de alegría y le comenta de una gran fiesta que se realizará en Bogotá por el retorno de los jesuitas. El Arzobispo tenía la convicción de que con el aporte académico y pastoral de la Compañía la situación de la Iglesia mejoraría substancialmente, pues se quejaba por que no encontraba interlocutores entre sus colegas con los cuales reformar el poco clero que existía en la Nueva Granada. Este sentimiento de optimismo se ve reflejado en las siguientes palabras:

[... y vamos a ver si en el año entrante tenemos aquí a los jesuitas. ¿No cree usted esto un sueño? Así me parece, y yo he dicho mil veces: a Domino factum est istud, et est mirabile in occulis nostris. Si los Jesuitas vienen, Dios ha alzado ya su azote (Cuervo, 1922, pp. 270-271).

Para hacer posible esta iniciativa monseñor Mosquera escribió una pastoral a los feligreses invitándolos a colaborar con limosnas. En una carta dirigida al gobierno neogranadino expresó a los legisladores su satisfacción porque mediante esta ley se emprendería nuevamente la evangelización de los indígenas y por la acertada medida de llamar para cumplir con este acometido a los jesuitas, religiosos que por su celo, sabiduría y virtudes cristianas cumplían con todos los requisitos necesarios para emprender grandes obras entre la población. Según él: "este es el juicio que de ellos han formado hombres distinguidos en Europa y América, y la experiencia va cada día confirmándolo" (Mosquera, 1842) ${ }^{3}$.

${ }^{3}$ Estas palabras dejan entrever el gran respeto y afecto que sentía este prelado por la Compañía de Jesús. La carta forma parte de un documento que se publicó en Bogotá como preparación remota al retorno de los religiosos. Se trató de una recopilación de artículos que mostraban opiniones favorables de historiadores y papas sobre su labor, la cual se conoció con el título Restablecimiento de la Compañia de Jesús en la Nueva Granada o Colección de piezas relativas a la historia de los Jesuitas y a su restablecimiento (1842). 
Desde la llegada de los jesuitas a Santa Marta en 1844, monseñor Mosquera, que recibía noticias del regreso paso a paso, fue disponiéndolo todo desde Bogotá para que fueran acogidos y bienvenidos por los feligreses de los lugares por donde pasaran con fiestas y otra serie de actos religiosos. En una carta del 22 de marzo de 1844 comenta:

Con indecible placer he recibido la estimada de V. R. de 28 de febrero, que me ha traído la deseada noticia del feliz arribo de los hijos del Grande Ignacio a la Nueva Granada. Sean bienvenidos en el nombre de Jesús, bajo cuya enseña pelean los combates del Señor, y doy a su Majestad mil humildes gracias, porque en medio de tantas tribulaciones como nos rodean se digna consolarnos enviándonos un apostolado. Yo tengo mucha fe en todo lo que dejó escrito Santa Teresa de Jesús, y ella nos dice, como recibido de Dios, que la Compañía hará grandes cosas en los últimos tiempos. El Rmo. P. General me escribió en el año próximo pasado que enviaría gente escogida, y no dudo que Nuestro Señor ha de haber alumbrado a su Rma., en la elección de los sujetos con que ha formado la Misión de la Nueva Granada (Pérez, 1896-1898, pp. 44-45) .

Al parecer era tal la confianza del prelado en la Compañía, que casi inmediatamente les dio a sus religiosos plenas facultades ordinarias y extraordinarias para ejercer los ministerios sin restricción alguna en su jurisdicción episcopal. La amistad y las buenas relaciones del arzobispo Mosquera con los jesuitas le acarrearon varios disgustos con el clero local. En la correspondencia entre 1847 y 1850 narra a su hermano Manuel María las vicisitudes que tuvieron que afrontar los ignacianos readmitidos, entre otras, el trámite de pro-

${ }^{4}$ Este fervor se ve igualmente en los obispos de Popayán, Fernando Cuero y Caicedo, y de Antioquia, Juan de la Cruz Gómez Plata, quienes también colectaron fondos entre el clero y las feligresías de sus diócesis para costearle el viaje desde Europa al grupo de jesuitas y para apoyar el fondo de misiones. Una vez establecidos en el antiguo convento de San Francisco en Popayán (donde funcionará posteriormente el noviciado), el obispo Cuero les solicitó a los ignacianos recién llegados que se encargaran del seminario de su diócesis. Lo mismo hizo el obispo Gómez, quien les ofreció en muchas ocasiones el gobierno del seminario de Santafé de Antioquia con sus rentas. Estos prelados encomendaron sus seminarios a los jesuitas porque creían en su ortodoxia teológica y filosófica y porque querían a toda costa promover la educación y la instrucción de sus respectivos cleros. 
yectos en las Cámaras de Antioquia y Vélez que buscaban prohibirles educar a la juventud, y crecientes y reiterados rumores de una nueva expulsión del país. $\mathrm{Al}$ respecto comenta: "la guerra sorda que me hacen a mí personalmente, a los jesuitas, a los dos Seminarios y a la Propagación de la fe, es guerra continua y que me causa daño" (Arboleda, 1956, p. 235).

En otra carta de 1848 expone su sentimiento de pesadumbre ante las nuevas fuerzas políticas que gobiernan y que evidentemente estaban en contra suya y de la presencia de la Compañía. Según le dice a su hermano, era consciente de la mala fama que tenía entre los sacerdotes de su Arquidiócesis y de los desfavorables informes entregados por el representante del Vaticano al Papa. Y aunque encarece mantener el secreto de sus cartas, el Arzobispo manifiesta sus sentimientos de tristeza frente a un clero secular y regular politizados y que no acatan sus exhortaciones, desobediencia que se hacía extensiva al pueblo en general dada la profunda influencia de la institución eclesiástica. Como corolario de su frustración expresa: "Soy ya inútil, y no puedo esperar más que azares” (Arboleda, 1956, p. 240).

Una vez expulsados los jesuitas en 1850, el Arzobispo invitó a sus feligreses a mantener la calma y asumir con fe y paciencia las determinaciones del gobierno de José Hilario López (Mosquera, 1858, pp. 199-200). Si bien emitió este comunicado, es innegable el sufrimiento que generaron en el prelado estos hechos, tal como se lo comunicó al padre Pablo de Blas, superior en Pasto que se refugió en Ecuador tras la expulsión. Aunque ese gesto de acogida del gobierno del vecino país le causara cierta alegría, Mosquera escribe:

Mi salud ha quedado muy quebrantada y aunque fui a recuperarme al campo, y logre efecto alguno, al segundo de mi regreso han reaparecido los achaques del corazón que está ya lacerado materialmente. Sufrir, será lo que Dios quiere 5 .

Pese a la escasez de personal y a las dificultades a las que se enfrentó el prelado durante su gestión administrativa y pastoral, la Arquidiócesis creció significativamente. En un informe enviado al Congreso el 16 de diciembre de 1846 se registra que su jurisdicción contaba con 328 iglesias parroquiales, 24 iglesias vice-parroquiales, 79 capillas particulares y 30 ermitas. Estos estable-

${ }^{5}$ AHPCSJ, Carta de Monseñor Manuel José Mosquera al P. Blas, Bogotá, 14 de agosto de 1850, Estante 2, Caja 68, f. 137. 
cimientos eran atendidos por 246 curas párrocos. El número de seminaristas era significativo pues contaba con 95 seminaristas estudiantes de teología y 174 seminaristas estudiantes de filosofía. Al clero secular se le sumaban seis órdenes religiosas que colaboraban en la labor pastoral: los dominicos, los franciscanos, los hermanos hospitalarios de San Juan de Dios, los jesuitas, los agustinos calzados y los agustinos descalzos. (AGN, 1846, ff. 536-539).

Tras la expulsión se secularizó el seminario, argumentando que bajo el régimen de López los aspirantes a la carrera eclesiástica se educarían mejor y sin fanatismos. El pueblo católico en general veía de esta manera desaparecer el único plantel en el que se enseñaba la religión y la moral, lo cual generó una profunda decepción (Cavelier, 1989, p. 269). En mayo de 1851 el Congreso neogranadino arremetió contra el fuero interno de la institución católica. En dichas sesiones se prohibió de nuevo la entrada de los jesuitas y se acordó que las autoridades civiles no obligarían a ningún religioso a cumplir con sus votos. Asimismo, se le prohibió al arzobispo Mosquera hacer uso del breve pontificio que le permitía visitar y reformar los conventos y comunidades de sacerdotes regulares existentes en el país. También se abolió el fuero eclesiástico, con lo cual los clérigos y obispos quedaron sujetos a los tribunales y jueces de la República en caso de tener un mal desempeño en las funciones pastorales (Restrepo, 1963, p. 186).

En mayo de 1851, mediante una ley se dispuso que los cabildos parroquiales fueran los encargados de elegir a los curas que les presentaran sus respectivos obispos para las parroquias. Estas medidas y las que afectaban sus intereses económicos, llevaron a un grupo de conservadores a promover un levantamiento armado que culminó en la guerra civil de 1851 .

\section{El ARZOBispo Antonio HerRÁn y Zaldúa, 1855-1868}

Varios hechos sucedieron en la Nueva Granada luego de la expulsión de los jesuitas en 1850. El gobierno de José Hilario López fue radicalizando sus posiciones con la Iglesia hasta lograr el juicio y la expulsión del arzobispo Manuel José Mosquera y otros obispos que no se sometieron a su intervencionismo. En los primeros meses del gobierno de José María Obando las relaciones con la Iglesia fueron buenas pero más adelante el Presidente radicalizó sus posturas y rompió relaciones con el delegado Apostólico, monseñor Lorenzo Barili, quien había protestado contra las medidas intervencionistas del gobierno de José Hilario López en relación con la estructura de la Iglesia y de sus miembros. 


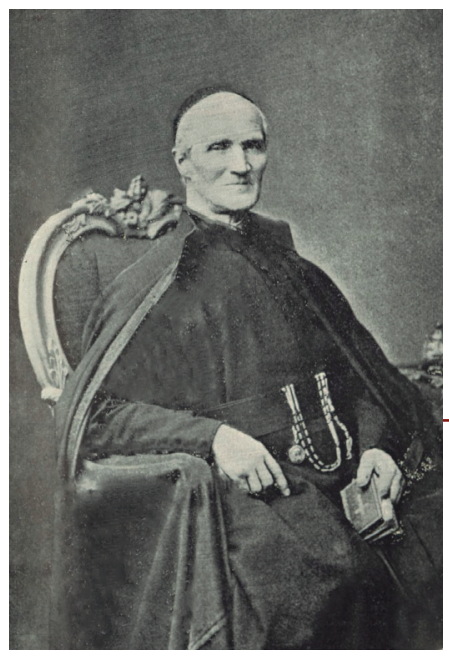

Figura 2. Anónimo. (1897). Pedro Beckx. En: Rafael Pérez., S.J. La compañia de Jesús en Colombia y en Centro América después de su restauración. Valladolid: Imprenta y heliografía y taller de grabados Luis N. de Gaviria. Vol. II p. 153.

Al final todas estas circunstancias derivaron en la declaración de la absoluta independencia entre la Iglesia y el Estado el 15 de junio de 1853.

Al mismo tiempo, la situación social y política se fue tornando cada vez más compleja, principalmente por las demandas de mayor participación y reales reformas económicas adelantadas por el sector de los artesanos. El descontento fue aprovechado por el general José María Melo, comandante de la plaza de Bogotá, que lideró el golpe de Estado del 17 de abril de 1854. El golpe del general Melo se realizó contra la facción de los Gólgotas, que eran jóvenes, en su mayoría de clases altas y con firmes posiciones en contra de la Constitución de 1853. Melo representaba a la fracción de los Draconianos entre quienes se encontraban militares de origen humilde y artesanos de la Sociedad Democrática. Estos últimos participaron como guardias y fuerza policial en la capital. Esta situación de golpe y las pugnas internas constantes entre los miembros del partido liberal hicieron que los conservadores recobrarán el poder en 1855 (Valencia, 1998, pp. 37-57).

En ese momento, tras casi ocho años desde la segunda expulsión de los hijos de Loyola de la Nueva Granada, el arzobispo Antonio Herrán y Zaldúa, considerando que existían las condiciones favorables para su regreso, se comunicó con el superior general de la Compañía, el padre Pedro Beckx. Para dicha gestión el prelado contaba con la anuencia del presidente Mariano Ospina Rodríguez y del delegado apostólico Miecislao Ledochowski. En una carta el arzobispo Herrán le recordó al superior Beckx todas aquellas gestiones que realizó su predecesor en el restablecimiento de la Orden, y le pidió no desatender su llamado de enviar a sus religiosos para que le colaboraran en distintos menesteres en la Arquidiócesis de Bogotá: 
Hoy, Rev. P. Convencido yo, como el Ilmo. Sr. Mosquera lo estaba de la necesidad de coadjutores para no dejar perder en estos pueblos la fé i el catolicismo, i no teniendo en mi clero el número de operarios suficiente para atender a las multiplicadas atenciones que tengo sobre mí, no puedo menos que dirigirme a V.R. solicitando nuevamente que destine para el arzobispado de Bogotá algunos religiosos, que viviendo en comunidad puedan servir de directores i profesores en el seminario i servir también en las misiones cuyo restablecimiento es muy agradable a los ojos de Dios, por el culto que en ellas se le da i por las muchas almas que se ganan para el cielo. Aquí puedo poner a disposición de los padres que vengan el edificio del Colegio y contribuir para su manutención con todo cuanto pudiere, lo mismo que para su transporte. Además de esto, no hay ahora temores fundados de que suceda ahora lo que sucedió el año de 1850 en que se había adueñado del poder un partido anticatólico i enemigo del orden. El presidente de la República i los altos majistrados quieren la venida de los Padres Jesuitas porque están persuadidos de los muchos males que con su venida se evitaran i de los grandes bienes que con ella se conseguirán. El pueblo en masa clama por ellos, i me pide con insistencia solicite con V. R. su venida, como lo verá V.R. por la representación que con esta carta le dirijo, i en la que están estampadas las firmas de las personas más influyentes (citado en Restrepo, 1961-1963, pp. 324).

Ante esta petición formal del Arzobispado y de la sociedad civil, el Superior general, a través de su asistente Manuel Gil, le pidió al padre Pablo de Blas que se trasladara de Guatemala a Bogotá a restaurar la Compañía. El 24 de diciembre de 1857, Blas emprendió viaje acompańado de Luis Segura, Lorenzo Navarrete y el hermano Miguel Parés (aunque este último murió en el trayecto), dejando "[...] la misión de Guatemala floreciente y llena de vida con sus cinco casas en las cuales trabajaban con incansable celo 21 sacerdotes y 17 hermanos Coadjutores, y se formaban 30 jóvenes entre novicios y estudiantes" (Pérez, 1896-1898).

Los tres jesuitas llegaron a Bogotá el 18 de febrero de 1858. El primero de mayo siguiente, con permiso de la autoridad eclesiástica abrieron un noviciado gracias a la donación de una casa de la señora Agustina Fuenmayor. En sus tres años de permanencia en Bogotá ingresaron algunos jóvenes que más adelante serían los forjadores de la provincia colombiana, ellos fueron 


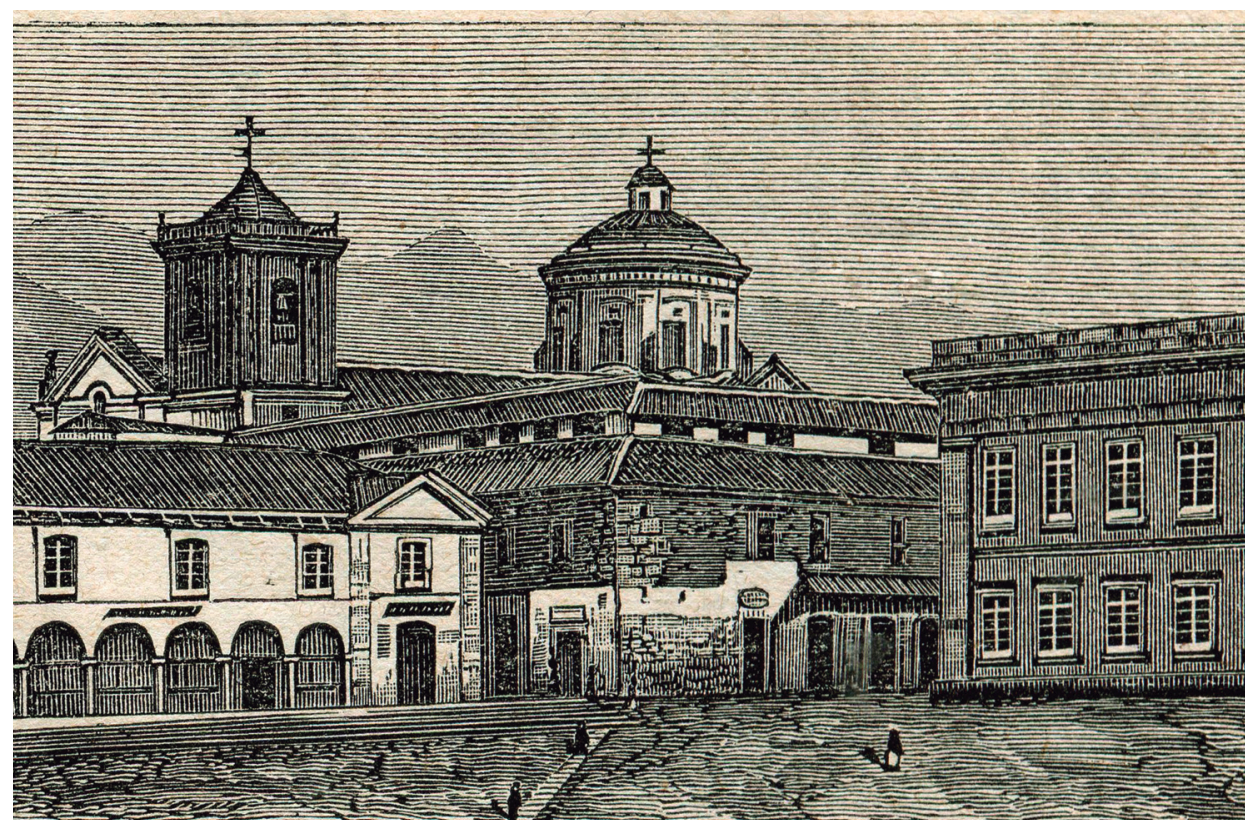

Figura 3. Francisco Javier Vergara y Francisco José de Vergara. (1881). Colegio de San Bartolomé. En: Almanaque y guía ilustrada de Bogotá. Bogotá: Imprenta de Ignacio Borda.

Mario Valenzuela, Daniel Quijano, Francisco Castañeda, Francisco Urdaneta, Santiago Páramo, Zoilo Arjona, Francisco Barreto, Teódulo Vargas y Javier Junguito, quien llegó a ser obispo de Panamá.

Ese mismo año el Gobierno nacional, a través del secretario de hacienda, entregó el colegio de San Bartolomé bajo arrendamiento al doctor Pastor Ospina, hermano del presidente, por un periodo de veinte ańos. Este estadista a su vez hizo contrato con los jesuitas recién llegados, quienes tomaron bajo su tutela el inventario de bienes del colegio y la enseñanza de las cátedras de idiomas y ciencias morales, matemáticas y físicas ${ }^{6}$. Con este convenio los religiosos adquirieron también la responsabilidad del régimen interno del establecimiento, el cual arreglaron de acuerdo con la metodología de la ratio Studiorum. En estas actividades permanecerían los tres jesuitas readmitidos en la ciudad de Bogotá, hasta la expulsión decretada por Tomás Cipriano de Mosquera en 1861.

${ }^{6}$ Las otras cátedras como jurisprudencia y medicina seguirían bajo la dirección del contratista, el doctor Pastor Ospina. 
En 1863 se redactó una constitución política en el país que llevó a la división del partido liberal entre mosqueristas y radicales. Este será el comienzo del período denominado Olimpo Radical, durante el cual se asumieron más políticas intransigentes con la Iglesia católica.

En el campo eclesiástico, desde 1867 el arzobispo de Bogotá Antonio Herrán y Zaldúa dio inicio a un proceso de reorganización de la Iglesia en el país, siguiendo las recomendaciones del papa Pío IX. Herrán convocó el primer Concilio Provincial, pues según él, era un momento oportuno para reunir a la jerarquía eclesiástica (Agudelo, 2010, pp. 482-495).

La división entre los miembros del liberalismo y la confrontación constante con los jerarcas de la Iglesia llevó a que más adelante, el político liberal Rafael Núñez -presidente del Congreso durante el gobierno de Julián Trujillo en 1878-, lanzara la célebre frase que se convirtió en el emblema de su gobierno "Regeneración o Catástrofe". En 1880 Núñez fue elegido como presidente y mediante su lema intentó acercar a los diferentes actores políticos para lograr la paz política y religiosa del país. Sin embargo, el periodo que va de ese momento hasta el año 1900 se caracterizó por guerras sucesivas, anarquía política y una desorganización administrativa que dejaron al país dividido y empobrecido. La agudización de las pugnas entre los partidos políticos y las guerras civiles de 1876, 1885, 1895 y finalmente 1899 -conocida como la Guerra de los Mil Días y que dejó, entre otras consecuencias, la separación del Estado de Panamá-, marcaron el comienzo y el final de esta época de la historia colombiana (Ortiz, 1998, pp. 105-170).

Entre tanto se fue fraguando una tercera readmisión de la Compañía de Jesús, en parte debido al desgaste político sufrido por el radicalismo, pero principalmente por las gestiones del arzobispo Arbeláez. En 1872, observando el inminente destierro que iban a sufrir los jesuitas en Nicaragua, el prelado se dirigió al obispo de Panamá, Ignacio Antonio Parra, con las siguientes palabras:

Por el último correo que llegó del Atlántico supe que continuaban los Gobiernos de esas Repúblicas empeñados en llevar a cabo el inicuo plan de desterrar a todos los PP. de la Compañía residentes en dichas Repúblicas. Como su Reverencia muy bien sabe esta fue la suerte que corrieron aquí desde el año 1861, en que triunfó el Gobierno revolucionario y anticatólico que hoy domina. Sin 
embargo de que esta es la verdad, creo que si los Padres de la Compañía vinieran aquí, no como Comunidad religiosa sino como Sacerdotes particulares, podrían ayudarme mucho, hacer mucho bien; y el Gobierno, aunque no recibiera bien esto, no se atreverá a perseguirlos. Como esta es una cuestión que su Reverencia puede meditar, yo me atrevo a proponérselo, teniendo en cuenta que por mi parte, así como de toda la parte sana de este país, serían recibidos con entusiasmo (Restrepo, 1946, p. 84).

Estos buenos deseos se concretaron al inicio de 1884, fecha en la que se estableció una pequeña residencia en Bogotá con la cual se daba inicio en términos jesuíticos, a la Misión Colombiana de los hijos de Loyola. Más adelante, el vicario general Patricio Plata, quien gobernaba temporalmente la Arquidiócesis tras la muerte del arzobispo Arbeláez en junio de ese año, puso a disposición de los jesuitas el templo adjunto a La Enseñanza para que ejercieran sus labores apostólicas y sacramentales ${ }^{7}$.

\section{Arzobispo José Telésforo Paul Vargas, 1884-1889}

José Telésforo Paul Vargas fue el primer jesuita en ser arzobispo de Bogotá, ciudad en la que nació en 1831. Ingresó a la Compañía de Jesús en 1844, realizando su noviciado en Popayán y luego parte de su formación humanística y filosófica en Bogotá. Debido a la expulsión de los hijos de Loyola de la Nueva Granada en 1850, tuvo que salir hacia Bélgica y Francia en donde continúo su formación teológica y fue ordenado sacerdote. En 1857 regresó a América Central para apoyar la labor de los jesuitas en Guatemala en donde estuvo desde mediados de ese año hasta octubre de 1858, cuando lo destinaron a Bogotá. En esta ciudad apoyó la labor apostólica de sus hermanos como ayudante del maestro de novicios y como predicador. De Bogotá salió

${ }^{7}$ De todas maneras, debe decirse que según Restrepo Posada, en el mes de diciembre de 1883 un grupo de jesuitas estaba instalado de manera clandestina y su superior era Mario Valenzuela. (Cfr: Restrepo, 1961-1963, p. 427). En efecto, el padre Mario Valenzuela se trasladó de Panamá a Bogotá y le recomendó a su hermana que mantuviera en reserva este viaje y "que procurase que la prensa no hiciera ruido, para no exasperar a los adversarios de la Compañía y del Clero (Cfr. Restrepo, 1946, p. 88). 
Figura 4. Anónimo. (s. f.). Arzobispo José Telésforo Paul. En: Galería de notabilidades colombianas. Bogotá: Biblioteca Luis Ángel Arango. Reg: FI 439.

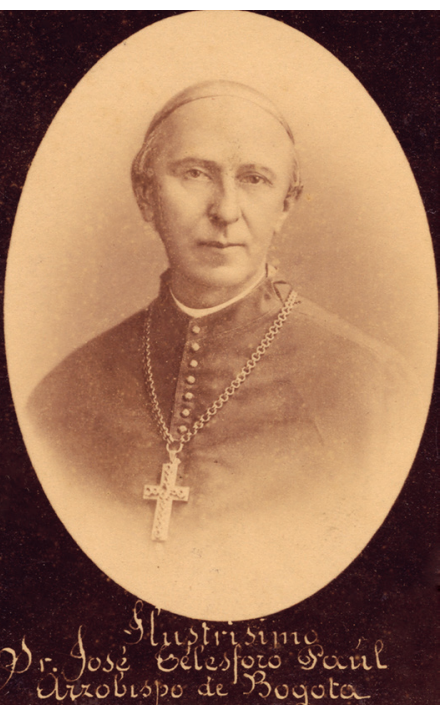

expulsado nuevamente con sus hermanos religiosos el 26 de julio de $1861^{8}$. Entre este ańo y 1869 fue profesor de teología y retórica en Guatemala y entre 1869 y 1872 fue superior de los jesuitas del Salvador, de donde salieron expulsados en junio de este último año, razón por la cual se vio forzado a viajar a la ciudad de Panamá para enseñar en el seminario (Cfr. Pérez, 1896-1898, pp. 300-304; Sariego, 1999). En esta ciudad tuvo que desarrollar su actividad pastoral y apostólica de manera clandestina para evitar ser objeto de persecución?. El obispo de Panamá, Ignacio Antonio Parra, les brindó su protección y cuando este fue movido a la diócesis de Pamplona, el papa Pío IX nombró a Paul Vargas en su reemplazo el 17 de septiembre de 1876. Después del deceso del arzobispo de Bogotá, Vicente Arbeláez Gómez, Paul fue designado arzobispo de esta sede por el papa León XIII el 6 de agosto de 1884, posición que ocupó hasta su muerte en 1889.

El 10 de septiembre de 1885 el presidente Rafael Núńez pidió a cada uno de los estados que enviaran dos delegados al Consejo Nacional para comenzar a cambiar la Constitución de 1863. En este consejo participaron nueve miembros del partido conservador y nueve del partido independiente. El arzobispo Paul

${ }^{8}$ Para una biografía más completa se pueden consultar: Restrepo (1961-1963, pp. 480559), Vargas (1964, pp. 7-17) y Mosquera (1938, pp. 81-158).

${ }^{9}$ Los sacerdotes José Telesforo Paúl Vargas y Roberto Pozo, en compañía del hermano coadjutor Heladio Rojas abrieron una residencia en la ciudad de Panamá (Cfr. Restrepo, 1940, p. 255). 
tuvo un papel crucial en la redacción de la constitución de 1886, pues fue cercano a Miguel Antonio Caro, uno de los redactores de la misma. Según Mosquera Garcés, Paul "redactó la parte relativa al problema religioso, y fue opuesto a que se abrieran para el clero los campos de la actividad oficial, limitando su influencia al simple terreno de la beneficencia y de la instrucción pública” (Mosquera, 1938, p. 149). Con respecto a Núnez y Caro, Paul escribió en el periódico La Nación:

Si para Colombia el señor Dr. D. Rafael Núñez es el hombre providencial que destronó y arrojó de este suelo la anarquía demoledora y sacó del abismo la nave del Estado, no es menos providencial el Sr. D. Miguel Antonio Caro, en quien Dios ha puesto la luz del genio, la fuerza que nada teme y la decisión por la verdad que son necesarias para guiar a los pueblos a su moral grandeza. Estos dos egregios hombres se comprenden y se respetan, no se envidian y se aman y de acuerdo trabajan por fundar la sociedad sobre bases inconmovibles ${ }^{10}$.

Paul también fue el responsable de la elaboración del Concordato entre la Santa Sede y el gobierno de la República de Colombia. Igualmente fue apreciado por el clero bogotano y favoreció el establecimiento definitivo de los miembros de la Compañía de Jesús, que hacían presencia en el país desde 1883.

\section{Arzobispo Ignacio LeÓn Velasco, 1889-1891}

Antes de ser nombrado arzobispo de Bogotá, Ignacio León Velasco había sido consagrado obispo de Pasto en marzo de 1883. Desde su sede, le solicitó al superior de los jesuitas Mario Valenzuela el envío de un grupo de misioneros para restaurar las misiones en el Putumayo y Caquetá y otro grupo para fundar un colegio y dirigir el seminario. Este último objetivo se logró con la apertura del Colegio al cual se añadió el seminario en 1885 (Restrepo, 1940, p. 256). Después de la muerte del arzobispo José Telesforo Paul fue nombrado para sucederle en la sede metropolitana.

Velasco ingresó a la Compañía de Jesús en 1847 en la ciudad de Popayán y en 1850 cuando se decretó la expulsión de sus formadores, siguió a sus maestros

${ }^{10}$ Carta de José Telésforo Paúl a Juan Antonio Zuleta, redactor de La Nación (Cfr. Zuleta, et. al., 1889, p. 94). 


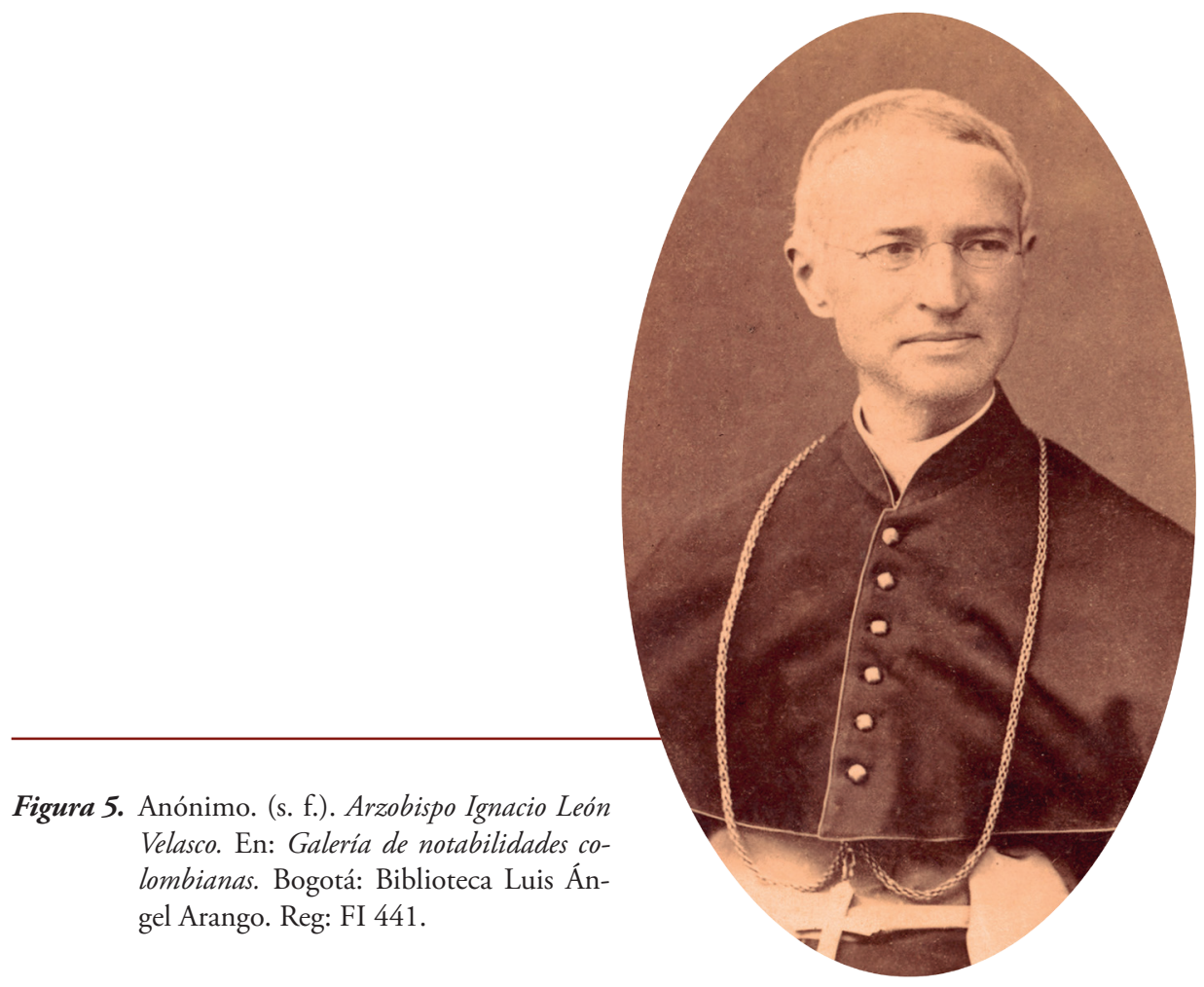

hasta Ibarra y luego a Quito, de donde fueron expulsados en 1852. Del Ecuador se trasladaron a Guatemala, donde concluyó los estudios humanísticos y filosóficos. En México hizo su etapa apostólica y fue ordenado sacerdote, pero por las constantes expulsiones que sufrieron los jesuitas en ese país, tuvo que salir en dos ocasiones, una para ir a estudiar teología en Salamanca y la otra en 1872 cuando fueron proscritos por el presidente Lerdo de Tejada. De allí se dirigió al Ecuador donde fue maestro de novicios. En 1876 regresó a México para fundar y ser rector del colegio de Saltillo. Estando en esta ciudad el papa León XIII lo designó para consagrarlo obispo de Pasto en 1883, oficio que ejerció hasta 1889, cuando fue llamado a reemplazar al arzobispo de Bogotá, cargo que desempeñó solamente durante año y medio debido a su repentina muerte a causa de una pulmonía infecciosa (Uribe, 1918, pp. 767-792).

A pesar de lo corto de su arzobispado, entre otras de sus obras pastorales y administrativas se destaca - para el tema que nos atañe en este escrito- el haber adelantado las gestiones entre los presbíteros bogotanos para devolverles a los jesuitas la iglesia de San Ignacio en 1891. 


\section{CONCLUSIÓN}

Los arzobispos de Bogotá Mosquera, Herrán, Arbeláez, Paul y Velasco (1835-1891) jugaron un papel crucial en el retorno y establecimiento de la Compañía de Jesús en el siglo XIX. Confiando en el liderazgo apostólico de los jesuitas, estos pastores coincidían en la necesidad de su presencia en las distintas ciudades y regiones del país, tanto como educadores de la juventud y del clero, como misioneros entre la población indígena. Por esta razón, no escatimaron esfuerzos para requerir a los superiores generales de la Orden la presencia de sus religiosos, ni para concederles todos los medios posibles para que reiniciaran su obra pastoral, en un periodo histórico (casi 56 años) en el cual se definieron muchos de los atributos culturales, espirituales y políticos de nuestra sociedad.

\section{REFERENCIAS}

Agudelo G. (2010). Los Arzobispos de Bogotá que han marcado nuestra historia, 1564-2010, Bogotá: Fernando Leyva Editores.

Arboleda J. (1956). Vida del Illmo. Sr. Manuel José Mosquera, Bogotá: Ministerio de Educación Nacional.

Archivo Histórico de la Provincia de Castilla de la Compañía de Jesús (AHPCSJ) Alcalá de Henares, España. Estante 2, Caja 68, f. 137.

Archivo General de la Nación (AGN) (1846). Fondo República, sección Curas y Obispos. T. XIX. 1846. Ff. 536-9.

Cavelier, G. (1989). Las Relaciones entre la Santa Sede y Colombia. Bogotá: Kelly.

Cuervo, L. (1922). Epistolario del Doctor Rufino Cuervo. Bogotá: Imprenta Nacional.

Dueñas, Á. (2004). El Ilustrísimo y Reverendisimo Señor Doctor Manuel José Mosquera dignísimo Arzobispo de la Arquidiócesis de Santafé de Bogotá, 18001853. Bogotá: Filigrana.

El Día (1842, marzo), 103.

Fernández, J. (1852). El Arzobispo ante la Nación, Bogotá: Imprenta del Neo-granadino.

Horgan, T. (1977). El arzobispo Manuel José Mosquera. Reformista y Pragmático. Bogotá: Kelly.

López, J. (1850, mayo). Decreto de expulsión de los jesuitas de la Nueva Granada en 1850. En: M. Ospina, Documentos importantes sobre la espulsión 
[sic] de los Jesuitas, Bogotá: Imprenta de El Día, por J. Ayarza, 1850. pp. 56-57. Recuperado de: http://www.bibliotecanacional.gov.co/recursos_user/ digitalizados/fpineda_45_pza2.pdf

Mantilla, L. C. (2004). Mitra y Sable. Correspondencia del Arzobispo Manuel José Mosquera con su hermano el General Tomás Cipriano (1817-1853). Bogotá: Academia Colombiana de Historia.

Mosquera, M. (1842). Comunicación del M. R. Arzobispo al Secretario del Despacho del Interior y Relaciones Exteriores. Bogotá: Focion Mantilla

Mosquera, M. (1858). Documentos para la biografia e historia del Episcopado del Ilustrísimo Señor D. Manuel José Mosquera, arzobispo de Bogotá. Paris: Tipografía de Adriano Le Clere.

Mosquera M. (1938). La ciudad creyente. Bogotá: Centro S.A.

Ortiz L. (1998). Guerra y sociedad en Colombia. En Las Guerras Civiles desde 1830 y su proyección en el siglo XX (pp. 105-130). Bogotá: Museo Nacional de Colombia.

Pacheco, J. (1946, marzo). Monseñor Manuel José Mosquera. Revista Javeriana, 122, 91.

Pérez, R. (1896-1898). La Compañia de Jesús en Colombia y Centro-América después de su Restauración. Valladolid: Imp., Lib., Heliografía y Taller de Grabados De Luis N. de Gaviria/ Imprenta Castellana.

Ravignan, G. (1845). De la existencia del Instituto de los Jesuitas, Valencia: Librería de Casiano Mariana.

Restablecimiento de la Compañia de Jesús en la Nueva Granada o Colección de piezas relativas a la historia de los Jesuitas y a su restablecimiento, (1842). Bogotá: Imp. de José Antonio Cualla.

Restrepo, D. (1940). La Compañia de Jesús en Colombia. Compendio Historial y Galería de Ilustres Varones, Bogotá: Imprenta del Sagrado Corazón.

Restrepo, D. (1946). Vida del Padre Mario Valenzuela, Bogotá: Editorial Pax.

Restrepo J. (1961-1963). Arquidiócesis de Bogotá, Datos biográficos de sus prelados. Bogotá: Lumen Christi.

Restrepo, J. M. (1963). Historia de la Nueva Granada. Bogotá: El Catolicismo.

Revuelta, M. (2006). Once calas en la historia de la Compañia de Jesús, "Servir a todos en el Señor". Madrid: Universidad Pontificia Comillas.

Sariego, J. (1999). Aquellos tenaces misioneros proscritos. Los jesuitas en la Centroamérica Moderna 1842-1896. Guatemala: Estudios Centroamericanos.

Uribe, G. (1918). Los arzobispos y obispos colombianos desde el tiempo de la Colonia hasta nuestros dias. Bogotá: Imprenta la Sociedad. 
Valencia, A. (1998). La revolución de Melo en las Provincias del Cauca. En Las Guerras Civiles desde 1830 y su proyección en el siglo XX (pp. 73-89). Bogotá: Museo Nacional de Colombia.

Vargas, G. (1964). El Arzobispo Paul y la transformación politica de 1886. Bogotá: El Voto Nacional.

Zuleta, J. et. al. (1889, noviembre 10). Homenaje de la Nación al Sr. Don Miguel Antonio Caro, 10 de noviembre de 1888. Bogotá: Imprenta de la Nación. 